\title{
Differences of Morphological Characteristics between Japanese Tomato 'CF Momotaro York' and Dutch Tomato 'Endeavour' with Single-truss Tomato Plants Grown at High Density
}

\author{
Kazuya MAEdA ${ }^{1}$, Masahumi JohKaN ${ }^{1}$, Satoru TsuKagoshi ${ }^{2}$ and Toru Maruo ${ }^{1}$ \\ ${ }^{1}$ Graduate School of Horticulture, Chiba University, Matsudo, Chiba 271-8510, Japan \\ ${ }^{2}$ Center for Environment, Health and Field Sciences, Chiba University, Kashiwa, Chiba 277-0882, Japan
}

(Received November 19, 2019; Accepted January 28, 2020)

\begin{abstract}
In this study, we investigated the differences between the Japanese cultivar 'CF Momotaro York' and the Dutch cultivar 'Endeavour' regarding their morphological characteristics and fruit yield under the low-node order pinching and high-density planting system. Fresh fruit yield was not significantly different between both cultivars. While the Japanese cultivar had lower total dry weight, had higher distribution rate to fruit. The Dutch cultivar had a lower extinction coefficient and higher integrated solar radiation at fruit truss. It also had a higher fruit temperature and respiration rate than the Japanese cultivar. These results indicated that the lack of difference in yield between both cultivars and lower distribution ratio to fruit in the Dutch cultivar might be due to higher consumption of photoassimilate, which led to higher respiration rate and fruit temperature caused by higher extinction coefficient.
\end{abstract}

Keywords : distribution, extinction coefficient, fruit temperature, fruit yield, respiration

\section{INTRODUCTION}

Dutch tomato cultivars have been bred with an emphasis on yield (Higashide and Huevelink, 2009) on the premise of long-term and high-wire system (hereinafter referred to as Dutch cultivation system). Many studies have compared the characteristics of Japanese and Dutch cultivars in order to clarify the factors of high yield (Matsuda et al., 2011a; 2011b; 2013; Kakita et al., 2015). The main reasons for the high yield of Dutch cultivars are low light extinction coefficient and high photosynthesis rate, resulting in high light utilization efficiency (Higashide and Huevelink, 2009).

On the other hand, Japanese tomato cultivars have been bred with an emphasis on quality rather than yield (Higashide and Huevelink, 2009), and the selection environments for tomato cultivars differ greatly between Japan and the Netherlands. Japanese cultivars have been selected in open fields subjected to water stress, whereas Dutch cultivars have been selected in a hydroponic condition. In addition, the cultivation method mainly focuses on relatively short plant heights, such as picking meristem in 6 to 8 stages and performed twice a year, or continuous pinching cultivation. In recent years, low-node and high planting density system has attracted attention as a distinctive Japanese cultivation system for stable production of highquality tomatoes (Johkan et al., 2013;2014; Kinoshita et al., 2014; Tewolde et al., 2016). Therefore, in order to clarify the varietal characteristics of Japan and the Nether- lands, it is necessary to compare those cultivars in the context of the cultivation methods in Japan and the Netherlands.

In this experiment, we focused on morphological characteristics of both Japanese and Dutch cultivars. The morphological difference between Japanese and Dutch cultivars in Dutch cultivation system has been already discussed in detail (Higashide, 2018). However, there is limited information on the morphological characteristics of both cultivars in low-node and high density planting system for high-quality fruit production. In low-node and high-density planting system, the light condition in the community tends to deteriorate due to a decrease in the amount of light transmitted to lower areas caused by the 45 times higher planting density compared with that in the Dutch cultivation system. As a solution to this problem, there are some reports of improvement in the training method and supplemental light within the community ( $\mathrm{Lu}$ et al., 2012a; 2012b; Johkan et al., 2013), but these were performed using only Japanese tomato cultivars. Therefore, the purpose of this study was to clarify the differences of Japanese and Dutch cultivars by focusing on the morphological characteristics and search for suitable morphological features for the Japanese-style cultivation. In order to evaluate the difference in morphological characteristics, we use 'CF Momotaro York' as Japanese cultivar, and 'Endeavour' as Dutch cultivar. These cultivars are cultivated widely in their respective country.

Corresponding author : Kazuya Maeda, fax: +81-47-308-8807, e-mail : maedak408@affrc.go.jp 


\section{MATERIALS AND METHODS}

Two tomato cultivars (Japanese cultivar 'CF Momotaro York', Takii Seed Corporation, Kyoto, Japan, and Dutch cultivar 'Endeavour', Rijk Zwaan, De Lier, the Netherlands) were used. The experiment was conducted in a north-south oriented greenhouse $(18 \mathrm{~m} \times 18 \mathrm{~m} \times 4.5 \mathrm{~m})$ covered with an ethylene tetrafluoroethylene film (F-CLEAN; AGC Grenn-Tech, Tokyo, Japan) at Chiba University from August 18 to December 27, 2018.

The seeds were sown in a cell tray filled with commercial substrate (Na-Terra; Mitsubishi Chemical Agri Dream Co., Ltd., Tokyo, Japan). The substrate consisted of vermiculite, peat moss and red clay soil, and germinated in a growth chamber maintained at $30^{\circ} \mathrm{C}$. Immediately after germination, the seedlings were moved into a chamber set to light / dark period of 14/10 hours, light / dark temperature of $23 / 18^{\circ} \mathrm{C}, \mathrm{CO}_{2}$ concentration of $1000 \mu \mathrm{mol} \mathrm{mol}{ }^{-1}$ and light intensity of $300 \mu \mathrm{mol} \mathrm{m} \mathrm{m}^{-2} \mathrm{~s}^{-1}$ and were raised for 3 weeks. The seedlings were then placed individually in 0.5 L pots filled with a mixture of coconut fiber and rice husks $(\mathrm{v} / \mathrm{v}=7: 3)$ and the pots were transplanted into 3 rows of a nutrient film technique hydroponic system with northsouth oriented gutters. In each row, 30 plants per cultivar were planted and the plants in the end row were border plants. The border plants were also excluded from the measurement. The planting density was 8.3 plant $\mathrm{m}^{-2}$, and the seedlings were fertilized using commercial nutrient solution (High-Tempo; Sumitomo Chemicals, Tokyo, Japan). The solution consisted of $7.1 \mathrm{mM} \mathrm{NO}_{3}{ }^{-}, 4.2 \mathrm{mM}$ $\mathrm{K}^{+}, 3.6 \mathrm{mM} \mathrm{Ca}^{2+}, 1.3 \mathrm{mM} \mathrm{Mg}{ }^{2+}, 1.6 \mathrm{mM} \mathrm{H}_{2} \mathrm{PO}_{4}^{-}, 2.5$ $\mathrm{mg} \cdot \mathrm{L}^{-1} \mathrm{Fe}, 0.25 \mathrm{mg} \cdot \mathrm{L}^{-1} \mathrm{Mn}, 0.17 \mathrm{mg} \cdot \mathrm{L}^{-1} \mathrm{~B}, 0.10 \mathrm{mg} \cdot \mathrm{L}^{-1}$ $\mathrm{Zn}, 0.03 \mathrm{mg} \cdot \mathrm{L}^{-1} \mathrm{Cu}$, and $0.05 \mathrm{mg} \cdot \mathrm{L}^{-1} \mathrm{Mo}$, adjusted to electrical conductivity of $1.2 \mathrm{dS} \mathrm{m}^{-1}$. All lateral branches were removed, and the shoot tip was pinched to retain three leaves above the first inflorescence. In addition, flowers were sprayed with a commercial hormonal solution (Tomato Tone; ISK Biosciences K.K., Tokyo, Japan) when the fourth flower in the inflorescence opened to enhance the fruit set and no fruit picking. In the greenhouse, the daily mean temperature and humidity were indicated at Fig. 1 but irradiance and $\mathrm{CO}_{2}$ concentration were not measured.

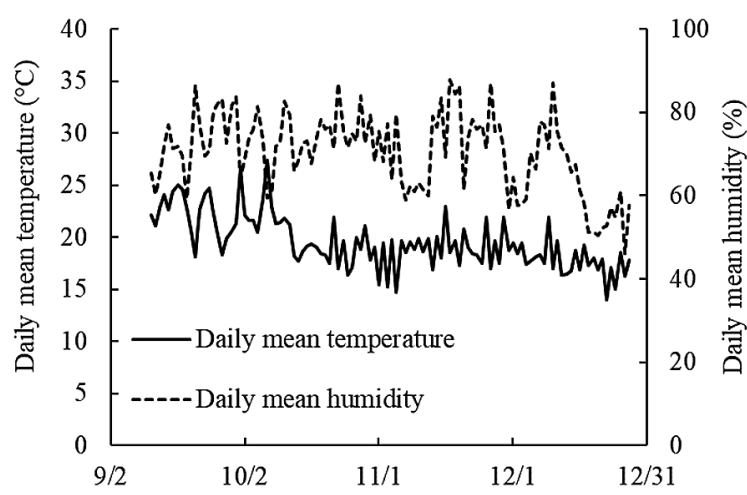

Fig. 1 Daily mean temperature and humidity in the greenhouse during experimental period.
The temperature inside the fruit core at red ripe stage was measured by inserting a thermistor (TR-5220, T\&D Corporation, Tokyo, Japan) from November 20 to December 5 and 3 fruits in each cultivar. The cumulative solar radiation at the fruit surface was measured from November 22 to 29 using an integrated solarimeter film (Optleaf R-2D; Taisei Chemical Co., Ltd., Tokyo, Japan). The film was cut into $5 \mathrm{~cm}^{2}$ and affixed to the fruits that were perpendicular to the growing bed. The fading rate was measured using a photometer (THS-470; Taisei Chemical Co., Ltd.) at a wavelength of $470 \mathrm{~nm}$, and the integrated solar radiation from the calibration curve was calculated by the film manufacturer (Taisei Chemical Co., Ltd.).

Four tomato fruits were collected at the mature green stage from each cultivar to evaluate the respiration rate. The fruit was weighed and sealed in $1 \mathrm{~L}$ container separately. After 2 hours, $1 \mathrm{~mL}$ of headspace gas was collected from the container by using micro-syringe:(MS-GAN100, Ito Corporation, Shizuoka, Japan) and carbon dioxide concentration was analyzed using a gas chromatograph (GC8APT, Shimadzu Corporation, Kyoto, Japan) equipped with a thermal conductivity detector (TCD). The respiration rate was determined based on carbon dioxide levels using a TCD equipped with parallel shunt column (ZY-1, Shimadzu Corporation, Kyoto, Japan). Helium (53.5 mL $\min ^{-1}$ ) was used as the carrier gas for the detection.

After harvesting the red ripe fruits, the sugar content and acidity were measured using a non-destructive sugar acidity meter (K-BA100R-1; Kubota Corporation, Osaka, Japan) and then placed in a dryer set at $90^{\circ} \mathrm{C}$ for 10 days, after which the fruit dry weight was measured. After the observation, the growth parameters and the dry weight of other plant parts were measured.

The stem length, stem diameter, and SPAD value were measured after harvesting. Then, 10 plants from each treatment were randomly selected for destructive harvesting. Each plant shoot was divided into leaves and stem parts and the materials were oven-dried at $80^{\circ} \mathrm{C}$ for 3 days to measure dry weight. The roots include pots and substrate were oven-dried at $80^{\circ} \mathrm{C}$ for 10 days and then measured total weight include the pot and substrate and finally subtracting the pot and substrate weight.

The individual-leaf area of each cultivar was obtained at the end of cultivation, the extinction coefficient was measured based on the canopy photosynthesis model (1953) of Monsi and Saeki (1953). The leaf area and PPFD were measured at 5 different height by using light sensor (LI-190R; LI-COR Lincoln, NE, USA) attached to light meter (LI-250A; LI-COR Lincoln, NE, USA) recorded the average value at 15 -minute intervals. The extinction coefficient was calculated from the following equation.

$$
I^{\prime} / I_{0}=\exp ^{(-k F)}
$$

$I^{\prime}$ : light intensity at each layer, $I_{0}$ : light intensity at the top of the community, $\mathrm{k}$ : extinction coefficient, $\mathrm{F}$ : integrated leaf area index from the top of the community to each layer.

In randomized replicated block design, ten plants were planted in each block, and three replicated blocks 
were analyzed and finally randomly selected 10 plants were used for growth and fruit yield measurements. Mean values were separated by $t$-test at the 0.05 significance level.

\section{RESULTS}

The stem length of the Dutch cultivar was 1.8 times longer than that of the Japanese cultivar (Table 1). However, there was no difference in the stem diameter of the cultivars. The fruit fresh weight and acidity did not differ between the cultivars, but the sugar content (Brix) was higher in the Japanese cultivar.

The total dry weight of the Dutch cultivar was $24 \%$ higher than the Japanese cultivar (Table 2). Regarding the dry matter distribution ratio, the Japanese cultivar had lower ratio to vegetative organs and higher to fruits.

The light extinction coefficient of the Japanese cultivar was significantly higher than that of the Dutch cultivar $(P<0.01)$, (Fig. 2). In other words, the Japanese cultivar had lower light transmissivity inside or below the community. The cumulative amount of light on the fruits' surface was higher in the Dutch cultivar than in the Japanese one (Fig. 3). Moreover, the fruit temperature of the Dutch cultivar was also higher. The daily average temperature was $17.8^{\circ} \mathrm{C}$ or the Japanese cultivar and $19.2^{\circ} \mathrm{C}$ or the Dutch cultivar. The biggest difference in fruit temperature between the cultivars was $5.4^{\circ} \mathrm{C}$ (Fig. 4).

As a result of measuring the fruit respiration rate in different temperature zones, the rate of the Dutch cultivar was significantly higher than that of the Japanese cultivar at $10^{\circ} \mathrm{C}$ and $20^{\circ} \mathrm{C}$ and also tended to be higher at $30^{\circ} \mathrm{C}$ (Fig. 5).

\section{DISCUSSION}

In this study, we compared Japanese and Dutch tomato cultivars grown under low node-order pinching and high-density planting system. The results showed that the Japanese cultivar had lower plant height and higher extinc-

Table 1 Stem length, stem diameter, SPAD values, fresh weight, total soluble solids and titrable acid of two cultivars.

\begin{tabular}{ccccccc}
\hline Cultivar & $\begin{array}{c}\text { Stem length } \\
(\mathrm{cm})\end{array}$ & $\begin{array}{c}\text { Stem } \\
\text { diameter }(\mathrm{mm})\end{array}$ & $\begin{array}{c}\text { Fruit fresh } \\
\text { weight } \\
(\mathrm{g} / \text { plant })\end{array}$ & $\begin{array}{c}\text { Number of } \\
\text { fruit } \\
\text { (fruit/plant) }\end{array}$ & $\begin{array}{c}\text { Total soluble } \\
\text { solids (Brix\%) }\end{array}$ & $\begin{array}{c}\text { Titratable } \\
\text { acid } \\
(\%)\end{array}$ \\
\hline CF Momotaro York & $72.4 \pm 0.6{ }^{\mathrm{z}} \mathrm{b}^{\mathrm{y}}$ & $9.8 \pm 0.1 \mathrm{a}$ & $701 \pm 25.8 \mathrm{a}$ & $4.1 \pm 0.2 \mathrm{a}$ & $5.9 \pm 0.1 \mathrm{a}$ & $0.4 \pm 0.02 \mathrm{a}$ \\
Endeavour & $130.1 \pm 0.7 \mathrm{a}$ & $9.6 \pm 0.2 \mathrm{a}$ & $685 \pm 13.0 \mathrm{a}$ & $7.2 \pm 0.1 \mathrm{a}$ & $5.5 \pm 0.1 \mathrm{~b}$ & $0.3 \pm 0.01 \mathrm{a}$ \\
\hline
\end{tabular}

${ }^{z}$ Mean $\pm \operatorname{SE}(n=10)$.

${ }^{y}$ Different letters withn a column indicate significant differences by Student's $t$-test $(P=0.05)$ in each cultivar.

Table 2 Plant total dry weight and fraction of dry weight partitioned to leaves, stem, fruit and root of two cultivars.

\begin{tabular}{cccccc}
\hline \multirow{2}{*}{ Cultivar } & Total dry weight & \multicolumn{4}{c}{ Dry mass partitioning (\%) } \\
\cline { 3 - 6 } & $(\mathrm{g} /$ plant) & Leaf & Stem & Fruit & Root \\
\hline CF Momotaro York & $76.9 \pm 1.9^{\mathrm{z}} \mathrm{b}^{\mathrm{y}}$ & $19.9 \pm 0.9 \mathrm{~b}$ & $10.2 \pm 0.4 \mathrm{~b}$ & $62.5 \pm 1.5 \mathrm{a}$ & $7.4 \pm 0.8 \mathrm{~b}$ \\
Endeavour & $95.5 \pm 1.0 \mathrm{a}$ & $26.3 \pm 0.7 \mathrm{a}$ & $16.7 \pm 0.5 \mathrm{a}$ & $48.3 \pm 1.2 \mathrm{~b}$ & $8.7 \pm 0.6 \mathrm{a}$ \\
\hline
\end{tabular}

${ }^{\mathrm{z}}$ Mean $\pm \operatorname{SE}(n=10)$.

${ }^{\mathrm{y}}$ Different letters within a column indicate significant differences by $t$-test $(P=0.05)$ in each cultivar.

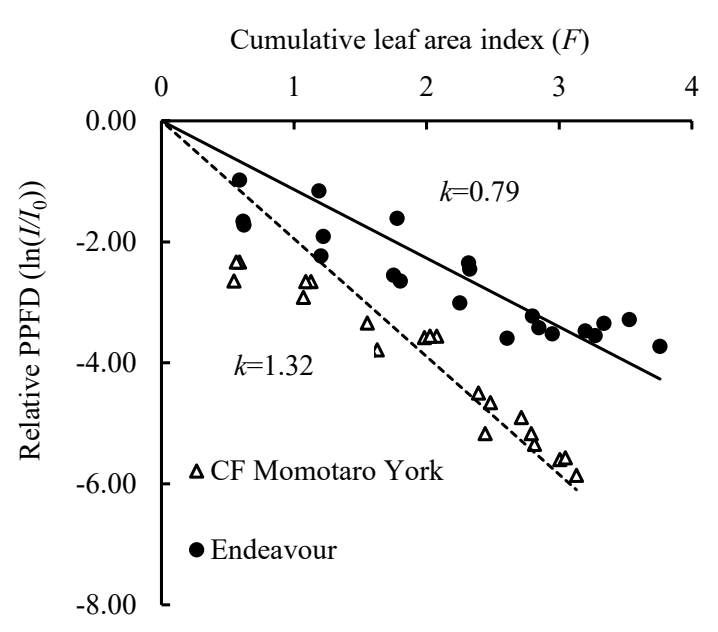

Fig. 2 Extinction coefficient $(k)$ of two different cultivars truss under a high-density growing system with the main stem pinched above the first truss. The value was tested on 2 December.

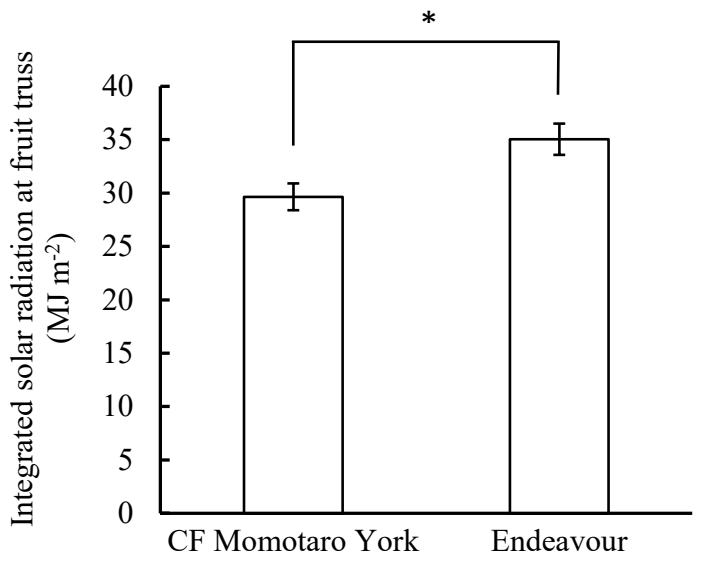

Fig. 3 Total integrated solar radiation at each tomato fruit truss under a high-density growing system with the main stem pinched above the first truss. The value is the average integrated solar radiation on 22-29 November, 2018. The values are means $\pm \operatorname{SE}(n=9 ; *$ Different at 0.05 significance level as indicated by Student's $t$-test). 


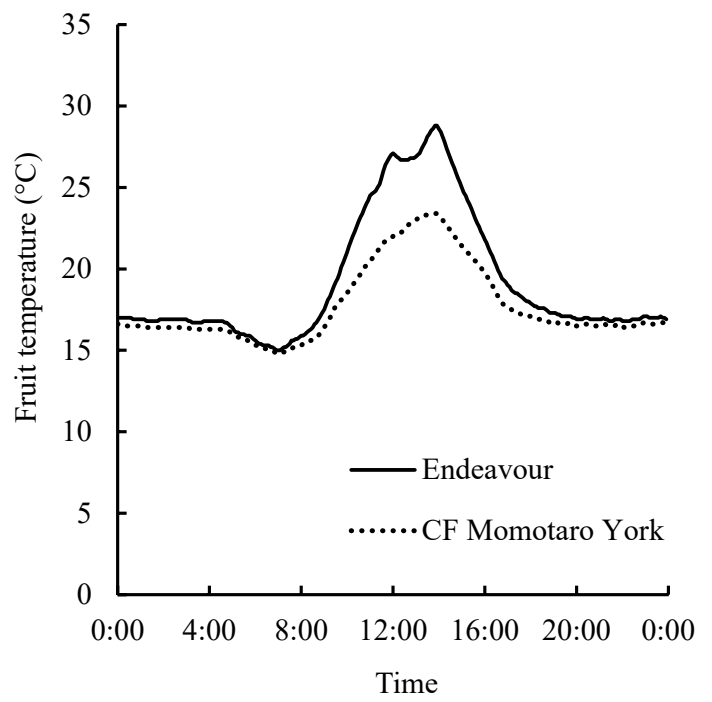

Fig. 4 The surface temperature of two different cultivars for tomato fruits under a high density growing system with the main stem pinched above the first truss. The value is the average temperature on 23 November, 2018.

tion coefficient (Table 1, Fig. 1). This tendency was the same as recorded in a previous study (Higashide et al., 2009) that compared Dutch and Japanese tomato cultivars with Dutch cultivation systems. However, the yield was shown to be different in that study. There was no difference in yield between the Japanese and Dutch cultivars in this study (Table 1). The total dry weight was higher in the Dutch cultivar and the higher distribution ratio to vegetative organ (Table 2). Higashide and Huevelink (2009) stated that the high yield of the Dutch cultivars is due to improved light utilization efficiency caused by the low light extinction coefficient and high photosynthetic capacity. Although the light extinction coefficient was also lower in the Dutch cultivar in this experiment, suggesting that the light utilization efficiency was higher in Dutch cultivar, this morphological characteristic did not affect the yield.

In the Dutch cultivation system, even if the extinction coefficient of Dutch cultivar is low, the fruit trusses at the enlargement stage are below the community, and solar radiation does not directly reach the fruit trusses. On the other hand, in low node-order pinching and high-density planting system, the plant height of the community is low. Although it depends on the internode length, leaf angle, and leaf area index, solar radiation may directly reach the fruit in the system. The Dutch cultivar, in particular, had a long internode and acute angle between the leaves and the stem, so that the fruits were easily exposed to direct light and fruit temperature became higher compared to the Japanese cultivar (Fig. 3). However, the temperatures might be influenced by the fruit size and the depth. Johkan et al. (2013) stated that AsA (ascorbic acid) increased in low node-order pinching and high-density planting system without the decrease in yield when the leaf above the fruit truss was lifted up to ensure that the fruit was exposed to sunlight, and this may be due to the higher fruit temperature. However, it is generally known that excessive

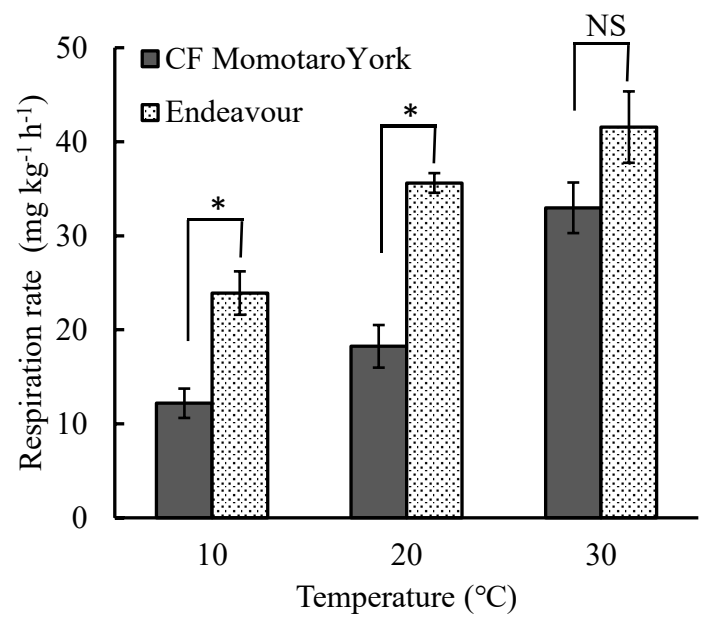

Fig. 5 Respiration rate $\left(\mathrm{mg} \mathrm{CO}_{2} \mathrm{~kg}^{-1} \mathrm{~h}^{-1}\right)$ of two different cultivars for tomato fruits at different temperatures. The values are mean $\pm \mathrm{SE}\left(n=4 ;{ }^{*}\right.$ Different at 0.05 significance level as indicated by Student's $t$-test). The parameter was analyzed by GC-TCD.

fruit warming reduces fruit yield of tomato. Adams et al. (2001) stated that when the fruit temperature was 15, 20, and $25^{\circ} \mathrm{C}$ the fruit weight was $75.8,73.8$, and $62.2 \mathrm{~g}$ respectively. In fact, the daily average fruit temperature was $17.8^{\circ} \mathrm{C}$ or the Japanese cultivar and $19.2^{\circ} \mathrm{C}$ for the Dutch one. Moreover, as a result of measuring the respiration rate of green fruits at different temperatures, the Dutch cultivar showed significantly higher values at $10^{\circ} \mathrm{C}$ and 20 ${ }^{\circ} \mathrm{C}$. These results suggested that the lack of difference in yield between both cultivars and lower distribution rate to fruit dry weight in total dry weight in the Dutch cultivar might be due to higher consumption of photoassimilate, which led to higher respiration rate and fruit temperature caused by higher extinction coefficient.

In conclusion, the Japanese cultivar used in this experiment had a high dry matter distribution ratio to the fruits and the high extinction coefficient to prevent an excessive rise in the fruit temperature. Those characteristics seemed to ensure fruit enlargement with low consumption of assimilates by respiration, and the high extinction coefficient as morphological characteristics is important for low node-order pinching and high-density planting system.

\section{REFERENCES}

Adams, S. R., Cockshull, K. E., Cave, C. R. J. 2001. Effect of temperature on the growth and development of tomato fruits. Ann. Bot. 88: 869-877.

Johkan, M., Ishii, M., Maruo, T., Na, L., Tsukagoshi, S., Hojoh, M., Nakaminami, A., Shinohara, Y. 2013. Improved light conditions at the fruit truss accelerate harvest time and enhance ascorbic acid concentration in a low-truss, high-density tomato production system. J. Jpn. Soc. Hortic. Sci. 82: 317-321.

Johkan, M., Nagatsuka, A., Yoshitomi, A., Nakagawa, T., Maruo, T., Tsukagoshi, S., Hohjo, M., Lu, N., Nakaminami, A., Tsuchiya, K., Shinohara, Y. 2014. Effect of moderate salinity stress on the sugar concentration and fruit yield in single-truss, high-density tomato production system. J. Jpn. 
Soc. Hortic. Sci. 83: 229-234.

Higashide, T., Heuvelink, E. 2009. Physiological and morphological changes over the past 50 years in yield components in tomato. J. Am. Soc. Hortic. Sci. 134: 460-465.

Higashide, T. 2018. Review of dry matter production and light interception by plants for yield improvement of greenhouse tomatoes in Japan. Hortic. Res. (Japan) 17: 133-146.

Kakita, T., Abe, A., Ikeda, T. 2015. Differences in root growth and permeability in the grafted combinations of Dutch tomato cultivars (Starbuck and Maxifort) and Japanese cultivars (Reiyo, Receive, and Magnet). Am. J. Plant Sci. 6: 2640-2650.

Kinoshita, T., Yano, T., Sugiura, M., Nagasaki, Y. 2014. Effects of controlled-release fertilizer on leaf area index and fruit yield in high-density soilless tomato culture using low nodeorder pinching. PLoS ONE 9:e113074.

Matsuda, R., Suzuki, K., Nakano, A., Higashide, T., Takaichi, M. 2011a. Response of leaf photosynthesis and plant growth to altered source sink balance in Japanese and Dutch tomato cultivar. Sci. Hortic. 127: 520-527.

Matsuda, R., Nakano, A., Ahn, D., Suzuki, K., Yasuda, K., Takaichi, M. 2011b. Growth characteristic and sink strength of fruit at different $\mathrm{CO}_{2}$ concentrations in a Japanese and Dutch tomato cultivars. Sci. Hortic. 127: 528-534.
Matsuda, R., Ahn, D., Nakano, A., Suzuki, K., Takaichi, M. 2013. Leaf gas exchange characteristics of four Japanese and four Dutch tomato cultivars grown in a greenhouse. Sci. Hortic. 156: 19-23.

Monsi, M., Saeki, T. 1953. Uber den Lichtfaktor in den pflanzengesellschaften und seine Bedentung for die Stottproduktion. Jpn. J. Bot. 14: 22-52.

Lu, N., Maruo, T., Johkan, M., Hohjo, M., Tsukagoshi, S., Ito, Y., Ichimura, T., Shinohara, Y. 2012. Effects of supplemental lighting within the canopy at different developing stages on tomato yield and quality of single-truss tomato plants grown at high density. Environ. Control Biol. 50: 1-11.

Lu, N., Maruo, T., Johkan, M., Hohjo, M., Tsukagoshi, S., Ito, Y., Ichimura, T., Shinohara, Y. 2012. Effects of supplemental lighting with light-emitting diodes (LEDs) on tomato yield and quality of single-truss tomato plants grown at high planting density. Environ. Control Biol. 50: 63-74.

Tewolde, T., Lu, N., Shiina, K., Maruo, T., Takagaki, M., Kozai, T., Yamori, W. 2016. Nighttime supplemental LED interlighting improves growth and yield of single-truss tomatoes by enhancing photosynthesis in both winter and summer. Front. Plant Sci. 7: 448. 